REJ - Revista de Estudios de la Justicia - No 4 - Año 2004

\title{
LA JURISDICCION UNIVERSAL Y LA CORTE PENAL INTERNACIONAL
}

\author{
Ximena Fuentes Torrijo*
}

\begin{abstract}
I. Introducción; II. La licitud del ejercicio de la jurisdicción universal en el derecho internacional; III. El fundamento de la jurisdicción de la corte penal internacional; IV. La relación entre la corte penal internacional y la jurisdicción universal.
\end{abstract}

\section{INTRODUCCIÓN}

Hasta el arresto de Augusto Pinochet en Londres para ser extraditado a España, donde se pretendía juzgarlo por la comisión de crímenes contra la humanidad, pocas personas en Chile se preocupaban de la jurisdicción universal. La ratificación de la Convención contra la Tortura de 1984 por el gobierno de Pinochet se hizo obviamente pensando que el ejercicio de la jurisdicción universal jamás alcanzaría a los actos de la dictadura chilena.

El único temor que parece haber rodeado a la ratificación de esta Convención por parte del gobierno de Pinochet parece haberse referido a posibles denuncias contra el Estado de Chile por parte de otros Estados en el tradicional esquema de una controversia interestatal. Eso explicaría la reserva al artículo 30 de la Convención contra la Tortura, presentada por Chile al momento de la ratificación, de no aceptar la jurisdicción de la Corte Internacional de Justicia para la solución de controversias relativas a la interpretación y aplicación de la Convención. Pero no hubo temor respecto de posibles demandas criminales contra individuos iniciadas en tribunales nacionales de países extranjeros. Y es que a 1988, fecha en que Chile ratifica la Convención contra la Tortura, existían muy pocos precedentes al respecto. A esa fecha la justicia criminal internacional puede señalar algunos casos de creación de tribunales internacionales para juzgar crímenes de lesa humanidad, como el tribunal de Nuremberg y el tribunal de Tokio, pero es muy poco lo que se puede exhibir en materia de ejercicio de jurisdicción universal por tribunales internos. El proceso más conocido hasta ese momento es el de Eichmann, en que los tribunales de Israel juzgaron efectivamente a Adolf Eichmann por los crímenes cometidos por éste en territorio extranjero y respecto de extranjeros; de hecho, cuando se cometieron esos crímenes Israel no existía como Estado. ${ }^{1}$ Posteriormente, en años más recientes hemos apreciado que algunos sistemas jurídicos nacionales están dispuestos a ejercer jurisdicción para perseguir crímenes contra la humanidad cometidos en el extranjero por extranjeros y contra extranjeros. En 1980, en Estados Unidos el caso Filartiga Peña-Irala marcó un precedente importante en esta materia al aplicar la Alien Torts Act y afirmar la jurisdicción de los tribunales estadounidenses respecto de un caso de tortura y asesinato ocurrido en Paraguay, en que tanto la víctima como el victimario

\footnotetext{
* Abogada, Licenciada en Ciencias Jurídicas y Sociales (Universidad de Chile), D.Phil (University of Oxford), Profesora de Derecho Internacional Universidad Adolfo Ibañez y Universidad de Chile.

${ }^{1}$ Attorney-General of the Government of Israel v. Adolf Eichmann. Israel, District Court of Jerusalem. Dec.

12, 1961. Supreme Court. May 29, 1962. Ver International Law Reports, vol. 36 (1968), pp. 5 y ss.
} 
Fuentes - La jurisdicción universal y la Corte Penal Internacional

eran paraguayos. ${ }^{2}$ En 1985 nuevamente los tribunales de los Estados Unidos se declararon competentes para conocer de una solicitud de extradición formulada por Israel respecto de un individuo que supuestamente había cometido crímenes de lesa humanidad en el campo de concentración de Treblinka (caso Demjanjuk). ${ }^{3}$ En 1989 los tribunales canadienses conocían el caso Finta, en que un ex gendarme húngaro era juzgado por la deportación de 8617 judíos desde Hungría a diversos campos de concentración Nazi. ${ }^{4}$

Actualmente los casos de ejercicio de la jurisdicción universal por la comisión de crímenes contra la humanidad han aumentado. México ha extraditado a un ciudadano argentino requerido por España para enfrenar allí cargos por la comisión de crímenes contra la humanidad en Argentina. ${ }^{5}$ España tramita varios casos criminales en contra de extranjeros por crímenes contra la humanidad cometidos en el extranjero. ${ }^{6}$ Los tribunales belgas también se han enfrentando a varios casos en que los demandantes solicitan el ejercicio de la jurisdicción universal. ${ }^{7}$ Se sostiene que alrededor de unos 12 países han establecido en su legislación formas de ejercicio de jurisdicción universal por diversos delitos. A esto debe agregarse también la consagración del principio de extraditar o castigar (aut dedere aut punire) en diversos tratados, ${ }^{8}$ que si bien, puede interpretarse en un sentido que no obliga a los Estados a establecer jurisdicción universal stricto sensu, ${ }^{9}$ sí parece obligarlos a cooperar con la jurisdicción universal que otros Estados pretendan, extraditando hacia ellos a los individuos requeridos.

Pero el ejercicio de la jurisdicción universal, que parece ser una conducta estatal, en principio, permitida por el derecho internacional, suele ser la fuente de controversias interestatales. Lo demuestra el propio ejemplo del caso Pinochet, en que el Estado de Chile como tal resistió el ejercicio de la jurisdicción universal que pretendían España y el Reino Unido. Las controversias que suscita el ejercicio de la jurisdicción universal, suelen estar acompañadas, en los casos de crímenes contra la humanidad, por la cuestión de la vigencia o no del principio de la inmunidad del Estado y sus funcionarios en estos casos. Recientemente, la Corte Internacional de Justicia se ha pronunciado en favor de la aplicación de la inmunidad de un funcionario en ejercicio de la República del Congo, cuya detención había sido solicitada por Bélgica. ${ }^{10}$ Sin embargo, en cuanto al desconocimiento de la inmunidad ratione materiae de ex-funcionarios, el caso Pinochet ha sentado un importante precedente. ${ }^{11}$

\footnotetext{
2 Filartiga v. Pena-Irala. U.S. Court of Appeals for the Second Circuit. 630 F.2d 876 (2d Cir. 1980).

${ }^{3}$ Demjanjuk case, 603 F. Supp. 1468 (ND Ohio), aff d 776 F. 2d 571 (6 $6^{\text {th }}$ Cir. 1985).

${ }^{4}$ R. v. Finta (1994) 1 S.C.R. 701.

5 Ver Suprema Corte, Amparo en Revisión 140/2002, Quejoso: Ricardo Miguel Cavallo, en $<$ www.scjn.gob.mx $>$.

${ }^{6} \mathrm{Ver}<$ www.u-j.info $>$.

7 Ver ibid..

8 Ver, por ejemplo, la Convención de Montreal para Combatir los Actos Indebidos contra la Seguridad de la Aviación Civil (1971), la Convención de la Haya para Combatir el Ataque Indebido contra Aviones (1970) y la Convención Internacional contra la Toma de Rehenes (1979)

9 Según Rosalyn Higgins, el principio aut dedere aut punire establecido en algunos tratados otorga un título convencional para el ejercicio de la jurisdicción, el cual no sería equivalente a un título de jurisdicción universal stricto sensu, ya que sólo surgiría en los estrechos presupuestos de hecho establecidos en la convención: Problems and Process. International Law and How We Use It, (Oxford, 1994), pp. 63-4.

${ }^{10}$ Ver CIJ, caso de Arrest Warrant (2002).

11 Regina v. Bartle and the Commissioner of Police for the Metropolis and others (appelants) Ex parte Pinochet (respondent), ver:

<www.parliament.the-stationery-office.co.uk/pa/ld199899/ldjudgmt/jd990324/pino1.htm>.
} 
Paralelamente al desarrollo del caso Pinochet, se negociaba el Estatuto de una futura Corte Penal Internacional con jurisdicción para juzgar individuos acusados de cometer crímenes de lesa humanidad. Se materializaba así una vieja idea con la cual se pretende contribuir a evitar la comisión de crímenes que atentan contra ciertos intereses básicos de la comunidad internacional y que trascienden las fronteras de los Estados. Frente a los conflictos que genera el ejercicio de la jurisdicción universal y el desconocimiento de la inmunidad estatal por parte de tribunales nacionales, algunos plantean que la Corte Penal Internacional puede además representar una buena solución, en la medida que podría evitar que los países ejerzan su jurisdicción universal para sancionar los delitos cometidos en el territorio de otros países. El derecho a juzgar se concentraría en la Corte Penal Internacional. En la base de este argumento parece encontrarse la idea de que la Corte Penal Internacional tendría una base de legitimidad mayor que la que hoy día poseen los tribunales internos que ejercen jurisdicción universal.

En este artículo me referiré precisamente a este aspecto de las relaciones entre la Corte Penal Internacional y el ejercicio de la jurisdicción universal por tribunales internos de los Estados. La pregunta es: ¿Otorga el Estatuto de la Corte Penal Internacional una solución a las contiendas de competencia que pueden surgir entre el Estado territorial, es decir, el Estado donde se cometió el delito, y los Estados que desean ejercer jurisdicción universal? Me adelanto a señalar que en mi opinión la respuesta es negativa, ya que el propio Estatuto de la CPI no da una solución a ese problema, y el artículo 10 señala que:

Nada de lo dispuesto en la presente parte se interpretará en el sentido que limite o menoscabe de alguna manera las normas existentes o en desarrollo de derecho internacional para fines distintos del presente Estatuto.

Con todo, se insiste por parte de la doctrina que una de las consecuencias prácticas que sería conveniente alentar es que los Estados que deseen ejercer jurisdicción universal se autolimiten, dejando entonces espacio para el actuar de la Corte. Esta autolimitación iría en beneficio de los propios Estados, ya que les evitaría el costo que tiene para ellos involucrarse en conflictos de jurisdicción con otros Estados. Esta práctica, en definitiva, podría constituir la base para la creación de una norma internacional consuetudinaria que gradualmente derogaría el título de la jurisdicción universal y centralizaría finalemente el ius puniendi internacional en la CPI, sin perjuicio del ejercicio de otros títulos de jurisdicción no controvertidos, o por lo menos no tan controvertidos como el principio de la universalidad, como son el de la territorialidad y el de la nacionalidad.

Este gran impacto que la Corte Penal Internacional podría tener a futuro, al poner algo de orden respecto del ejercicio de las jurisdicciones estatales, aparece a primera vista como una de las bondades que podría tener la creación de este tribunal; sin embargo, creo que es útil hacer ver también que, junto con los efectos positivos, puede haber efectos secundarios negativos. En particular, me refiero al efecto negativo que esto podría producir en las posibilidades que tienen los diversos actores internacionales de establecer una verdadera comunidad internacional de intereses básicos comunes que trascienden las fronteras de los Estados. 
Fuentes - La jurisdicción universal y la Corte Penal Internacional

Es claro que esta comunidad de intereses básicos no logra todavía alcanzar una forma madura de expresión que la haga enteramente legítima. Sin embargo, creo que es posible pensar en la existencia futura de una verdadera comunidad internacional que posea una voluntad política propia. ${ }^{12}$ Esa voluntad política representativa de una comunidad internacional amplia, es difícil de encontrar hoy día ya que debe sortear múltiples obstáculos que la acallan. Lo importante es que debe reconocerse que hay formas en que ella puede expresarse de mejor manera que en otras. En este contexto, la existencia y el ejercicio de un título de jurisdicción universal es uno de los elementos que puede ayudar a la creación de esta comunidad internacional de intereses básicos comunes y es por eso que en mi opinión no sería conveniente que la CPI se transformara en un obstáculo a la jurisdicción universal.

\section{LA LICITUD DEL EJERCICIO DE LA JURISDICCIÓN UNIVERSAL EN EL DERECHO INTERNACIONAL.}

En 1927, al examinar un caso de ejercicio de jurisdicción extraterritorial, la Corte Permanente de Justicia Internacional debió tomar una determinada perspectiva teórica que le permitiera enfrentar el asunto que se le había sometido. Las dos opciones que manejaba la Corte eran las siguientes: o bien decidía concebir las relaciones internacionales como relaciones de Estados originalmente libres, en que el derecho internacional viene a poner gradualmente restricciones mediante los tratados o la costumbre internacional, o, por el otro lado, decidía concebir las relaciones internacionales como relaciones ipso facto regidas por ciertos principios de derecho, algunos de ellos modificables a través de los tratados o la costumbre internacional. Aplicada a la controversia que había sido sometida al tribunal, la controversia del Lotus, la perspectiva teórica tendría una influencia decisiva en la decisión que finalmente tomara la Corte en torno a la cuestión de la legalidad de la jurisdicción extraterritorial. Si se adoptaba la visión de la libertad original de los Estados, la Corte presumiría el derecho de Turquía a ejercer jurisdicción sobre el teniente Demons y sólo lo rechazaría en caso de demostrarse la existencia de una regla prohibitiva en contrario; si se adoptaba la visión alternativa, entonces la Corte presumiría la ilegalidad del ejercicio de la jurisdicción extraterritorial de Turquía y sólo modificaría esta opinión en caso de identificar una norma permisiva pactada por las partes en algún tratado o en alguna costumbre internacional.13 La visión voluntarista de la Corte Permanente de Justicia Internacional la obligaba a tomar la primera opción, ya que no disponía de evidencias positivas para dar por establecidas reglas restrictivas en materia de jurisdicción extraterritorial. Actuar de otro modo la habría obligado a presumir ciertos principios de derecho internacional al margen de la voluntad de los Estados. ${ }^{14}$

\footnotetext{
12 Estas ideas han sido desarrolladas en la ponencia que presenté en el Seminario SELA 2003 (Seminario en Latinoamérica de Teoría Constitucional y Política), realizado en Cuzco, Perú, en junio de 2003: 'Puede el derecho internacional contribuir a prevenir la violencia' (de próxima aparición en el libro que reúne las ponencias).

${ }^{13}$ En 1927, la concepción voluntarista del derecho internacional concebía a la costumbre internacional como un acuerdo tácito.

${ }^{14}$ La CPJI estuvo dispuesta a asumir la existencia de principios al margen de un análisis detallado de la voluntad de los Estados en relación con el principio del respeto a la integridad territorial de los Estados, pero no quiso hacer lo mismo en el caso de las restricciones al ejercicio de la jurisdicción extraterritorial, salvo obviamente en lo relativo a la prohibición de aplicar materialmente esa jurisdicción en el territorio de un Estado extranjero sin el consentimiento de este último: CPJI, 1927, Ser. A, No. 10.
} 
En el año 2003 la pregunta sobre la legalidad del ejercicio de la jurisdicción extraterritorial sigue requiriendo de un sustrato teórico sobre el cual construir una respuesta. ¿Presuponemos la libertad o la regulación en materia de extraterritorialidad? Si bien la visión voluntarista del derecho internacional ya no representa la visión dominante, todavía existe incertidumbre sobre cuáles son los principios constitucionales del derecho internacional que debemos presuponer. Existe cierto consenso en cuanto al principio de la igualdad jurídica y de la integridad territorial de los Estados, pero no existe consenso en cuanto a un supuesto principio de territorialidad en el ejercicio de la jurisdicción, excluyente, en principio, de la extraterritorialidad. Algunos autores creen en la existencia de un principio de territorialidad que puede ser modificado por instancias de extraterritorialidad que se justifiquen según un test de razonabilidad. ${ }^{15}$ Por su parte, Rosalyn Higgins sostiene que no es correcto mirar la territorialidad como la regla y a las instancias de extraterritorilidad como excepciones a esa regla, sino más bien como normas complementarias, que coexisten una al lado de la otra. ${ }^{16}$ Ella también parece adherir a un cierto test de razonabilidad, lo que nos deja claro entonces que es posible compatibilizar una visión no libertaria del derecho internacional, es decir que no parte desde la libertad absoluta de los Estados en estas materias, con una visión en que la territorialidad no excluye per se el ejercicio de instancias jurisdiccionales extraterritoriales.

Una de las características de los actuales estudios sobre la jurisdicción universal (que es una de las formas de ejercicio de jurisdicción extraterritorial) es la omisión de un sustrato teórico que otorgue claridad sobre los presupuestos básicos que se manejan al analizar los conflictos de jurisdicción. Esto es grave por cuanto de un modo tácito parece estar transmitiéndose el mensaje de que la jurisdicción universal estaría en principio prohibida.

Cuando algunos autores, al preguntarse por la licitud de la jurisdicción universal, buscan evidencia sobre la supuesta existencia de una obligación de ejercer jurisdicción universal en determinados casos, implícitamente también están transmitiendo el mensaje que, a falta de esa norma, el ejercicio de jurisdicción universal sería ilícito. Los jueces Higgins, Kooijmans y Buergenthal, en su voto separado en el caso del Arrest Warrant ${ }^{17}$, parecen haber advertido el error evidente en que se incurre al tratar de condicionar la licitud de la jurisdicción universal a la existencia de una regla que la imponga como una obligación a los Estados. Prefirieron, entonces, estos tres jueces concentrarse en el ejercicio de la jurisdicción universal como un derecho de los Estados y concluyeron que en cuanto derecho a ejercer jurisdicción universal no existe en derecho internacional sino una norma emergente. Para llegar a esta conclusión, Higgins, Kooijmans y Buergenthal miran las legislaciones internas de los Estados para señalar que no existe una práctica uniforme, que muchas legislaciones nacionales, a pesar de adoptar una jurisdicción

\footnotetext{
15 Mann, 'The Doctrine of International Jurisdiction Revisited after Twenty Years', Recueil des Cours (1964), pp.11 y ss.

16 Higgins, op. cit., p. 58.

17 Se debe recordar que en el caso del Arrest Warrant (República Democrática del Congo vs. Bélgica, 2002) la Corte Internacional de Justicia no estimó pertinente pronunciarse sobre la cuestión de la legalidad del ejercicio de la jurisdicción universal por crímenes contra la humanidad. El 11 de abril del año 2000, Bélgica había emitido una orden de arresto internacional en contra de Abdulaye Yerodia Ndombasi, quien a esa fecha se desempeñaba como Ministro de Relaciones Exteriores de la República Democrática del Congo. La Corte declinó pronunciarse sobre el tema de la jurisdicción universal, cuestión que no fue controvertida por la demanda del Congo, y prefirió concentrarse en la violación al principio de la inmunidad del Estado y sus funcionarios en ejercicio.
} 
Fuentes - La jurisdicción universal y la Corte Penal Internacional

supuestamente universal, igualmente muchas veces requieren de algún vínculo que conecte los hechos con el Estado que pretende ejercerla. ${ }^{18}$ Observan también que muchos Estados no aprueban el ejercicio de jurisdicción universal. ${ }^{19}$ Concluyen, entonces, estos jueces que "la legislación y la jurisprudencia nacionales -esto es, la práctica estatal- es neutra en cuanto al ejercicio de la jurisdicción universal." $20 \mathrm{Y}$, si bien rechazan la idea de que la batalla contra la impunidad sólo se puede realizar en el ámbito de los tratados y los tribunales internacionales, excluyendo a los tribunales nacionales, ${ }^{21}$ no se atreven a declarar simple y llanamente lícito el ejercicio de la jurisdicción universal.

No es claro lo que quieren decir estos jueces al calificar la práctica estatal como neutra. Es la neutralidad de la práctica lo que al parecer los lleva a descartar la existencia de una regla de derecho internacional consuetudinario que otorgue el derecho a los Estados a ejercer jurisdicción universal. Como la práctica tampoco es suficiente para afirmar la regla contraria, esto es, la de la prohibición, entonces se limitan a afirmar que en esta materia existiría a lo más, por ahora, una regla emergente que otorga el derecho a ejercer jurisdicción universal. De esta manera, entonces, la invocación de esta poco familiar categoría de "prácticas neutras" permite a los juicios crear un limbo en que la conducta de los Estados no está permitida ni prohibida por el derecho internacional. Sin embargo, un juez que se enfrentara a un problema sobre la licitud o ilicitud de la jurisdicción universal en un caso determinado, no podría simplemente escudarse en este limbo al que se refieren los tres jueces en el voto que se comenta, sino que tendría que finalmente adoptar una decisión sobre condenar o aceptar el ejercicio de la jurisdicción universal por parte de un determinado Estado.

Al negarse a declarar lícita la jurisdicción universal y limitarse a señalar que en esta materia sólo existe un derecho emergente, la posición de los jueces Higgins, Kooijmans y Buergenthal no es tan neutra como la práctica por ellos analizada. Concuerdan los jueces con la siguiente cita a la novena edición del manual de Oppenheim:

Si bien no se puede afirmar la existencia de una regla positiva del derecho internacional que otorgue a los Estados el derecho a castigar a nacionales extranjeros por crímenes contra la humanidad de la forma en que lo están para, por ejemplo, castigar los actos de piratería, hay claros indicios de una evolución gradual de un principio significativo de derecho internacional a ese efecto.

Con esta cita queda claro que la balanza de los tres jueces parece finalmente inclinarse hacia una ilicitud prima facie del ejercicio de la jurisdicción universal, regla que, en opinión de ellos, comienza a ser modificada por una regla emergente de derecho internacional. Tal vez el empleo del término "derecho" a ejercer jurisdicción universal ha provocado esta visión de los jueces. Un derecho normalmente exige una obligación correlativa, que en el caso sería difícil de identificar. Más adecuado resultaría, en mi opinión, emplear el término "facultad" o "potestad". Desde el punto de vista de una "facultad", el rechazo que puede generar la jurisdicción universal en terceros Estados no

\footnotetext{
18 Párrafo 45.

19 Párrafo 48 .

${ }^{20}$ Párrafo 45.

${ }^{21}$ Párrafo 51.
} 
impactaría a la facultad, sino no en la medida que los rechazos lograran ellos transformarse en una norma prohibitiva de derecho internacional consuetudinario.

El análisis que emprenden estos tres jueces en su voto separado en el caso el Arrest Warrant (2001) es ilustrativo de la falta de una base teórica sobre la cual examinar la existencia o inexistencia de reglas consuetudinarias en esta materia. Al respecto las posibilidades están abiertas: se puede asumir la teoría del laissez faire expuesta por la CPJI en el caso Lotus respecto del ejercicio de los poderes soberanos del Estado juzgador, o se puede partir desde el concepto de soberanía territorial de los Estados en cuyos territorios ocurrieron los hechos juzgados y mirar el ejercicio de la jurisdicción universal como una violación prima facie del principio de no intervención. ${ }^{22}$ En ambos casos el concepto básico que se utiliza es el de soberanía estatal. En mi opinión, es correcto centrarse en ese concepto; es ahí donde debe estar la respuesta a nuestra pregunta. Se debe aceptar, en todo caso, que ninguna de las dos caras del concepto de soberanía es absoluta: la soberanía para prescribir respecto de conductas que suceden fuera del territorio no es absoluta y el principio de no intervención no es obstáculo para que la comunidad internacional se pronuncie respecto de cuestiones de derechos humanos. Si lográramos definir los contornos del concepto de soberanía, de paso contribuiríamos también a establecer cuál es la regla en materia de ejercicio de la jurisdicción universal. No es posible realizar aquí un análisis detallado de esta cuestión, sin embargo, se pueden señalar los factores que se debieran tomar en cuenta para llegar a una regla más o menos general en materia de jurisdicción universal:

1) Entre las facultades soberanas del Estado se encuentra la competencia para evaluar los diversos factores que lo lleven a decidir establecer jurisdicción extraterritorial, fundado en los diversos títulos de extraterritorialidad, entre los cuales se encuentra el criterio de la universalidad. Las decisiones que toman los Estados difieren en atención a diversos factores tales como el peso político de los Estados, su capacidad jurisdiccional, sus recursos financieros, la idiosincrasia de su pueblo, y otros. Por lo tanto, no existen formas puras en el ejercicio de la jurisdicción universal. ${ }^{23}$

2) La decisión de un Estado de ejercer jurisdicción extraterritorial en cualquiera de sus formas debe acomodarse a ciertos criterios de razonabilidad como los siguientes: debe existir consenso internacional en cuanto a la justificación del ejercicio del ius puniendi de los Estados, las penas prescritas para los delitos deben ser razonables, en general debe otorgarse prioridad en el juzgamiento al Estado territorial pues suele encontrarse en una mejor posición para administrar justicia en el caso particular, el interés que el Estado persiga a través del ejercicio de la jurisdicción extraterritorial debe ser un interés legítimo reconocido así por la comunidad internacional.

\footnotetext{
22 Ver Sammons, "The "Under-Theorization" of Universal Jurisdiction: Implications for Legitimacy on Trials of War Criminals by National Courts', en 21 Berkeley Journal of International Law (2003), pp. 111 y ss.

${ }_{23}$ Puede ser útil llamar la atención sobre el hecho de que tampoco existen formas "puras" de ejercicio de la jurisdicción territorial. La justificación interna del ejercicio de la jurisdicción territorial también se encuentra sujeta a una evaluación política y económica. En este contexto, la falta de uniformidad que existe en cuanto al ejercicio de la jurisdicción territorial, jamás ha llevado a alguien a decir que la facultad de ejercer jurisdicción territorial es sólo un "derecho emergente".
} 
Fuentes - La jurisdicción universal y la Corte Penal Internacional

3) Los Estados deben respetar las normas del debido proceso respecto de los inculpados. Los procedimientos criminales que se siguen en ausencia de los inculpados podrían ser calificados como contrarios a las normas del debido proceso.

4) En general, los Estados se encuentran obligados a respetar los principios de la inmunidad estatal, salvo que sea posible identificar normas de derecho internacional que los faculten para desconocer las inmunidades que pudieran afectar a determinadas personas.

5) También se encuentran obligados los Estados a respetar el principio de la integridad territorial de los otros Estados, de tal manera que sería ilícito ejercer sus facultades materialmente en el territorio del otro Estado sin que medie previamente la autorización del Estado del territorio.

Si reconocemos que el establecimiento y ejercicio de la jurisdicción universal es uno de los ámbitos de las decisiones políticas de los Estados y que el derecho internacional reconoce, en principio, legitimidad a ese ámbito en la medida que se respete un criterio de "lo razonable" y otras reglas de derecho internacional, entonces el punto de partida en cualquier análisis sobre jurisdicción universal debiera ser el principio de la libertad en su ejercicio. El criterio de "lo razonable" no siempre se cumple, pero basta decir para los efectos de este artículo que, en cuanto a crímenes internacionales se trata, el título de la universalidad pareciera estar justificado en los casos de los crímenes de guerra, el genocidio y la tortura.

\section{EL FUNDAMENTO DE LA JURISDICCIÓN DE LA CORTE PENAL INTERNACIONAL.}

La Corte Penal Internacional no ejerce jurisdicción universal. El título de la universalidad es uno de los criterios para el establecimiento de la jurisdicción extraterritorial de los Estados, pero no se aplica a tribunales internacionales o supranacionales, cuya jurisdicción deriva del consentimiento de los Estados que los crean.

La Corte ha sido creada por medio de un tratado: el Estatuto de Roma de 1998. Su jurisdicción deriva, en primer lugar, del consentimiento otorgado por los Estados parte en el tratado. Adicionalmente, la jurisdicción de la Corte podría derivar de un consentimiento ad-hoc otorgado por un Estado que no es parte del Estatuto pero que acepta la intervención de la Corte en un caso determinado. Finalmente, existe también la posibilidad de que la Corte conozca de un caso a requerimiento del Consejo de Seguridad de las Naciones Unidas y, por lo tanto, podría conocer delitos cometidos en el territorio de un Estado que no es parte del Estatuto. En este último caso, el fundamento de la jurisdicción de la Corte se encontraría en el consentimiento que el Estado del territorio hubiere otorgado a la Carta de las Naciones Unidas y, por ende, a las funciones allí encomendadas al Consejo de Seguridad, incluido por cierto el capítulo VII en virtud del cual anteriormente ya se ha entregado jurisdicción a tribunales penales como el Tribunal para la ex Yugoslavia y el Tribunal para Ruanda.

Para activar la jurisdicción de la Corte es necesario además que se cumplan algunas condiciones. En primer lugar, la jurisdicción debe ser activada a petición de uno 
REJ - Revista de Estudios de la Justicia - No 4 - Año 2004

de los Estados Parte que remite al Fiscal una situación delictiva de competencia de la Corte, o por una investigación iniciada por el Fiscal de conformidad con el artículo 15 del Estatuto. También podría activarse la jurisdicción de la Corte por una remisión que hiciera el Consejo de Seguridad al Fiscal, como lo señala el artículo 13(b).

En caso que la jurisdicción de la Corte fuera activada por un Estado Parte o por el Fiscal, la Corte sólo podrá ejercer jurisdicción, como lo señala el artículo 12, si al menos uno de los siguientes Estados es Parte del Estatuto o ha aceptado la competencia de la Corte:

a) El Estado en cuyo territorio haya tenido lugar la conducta de que se trate, o si el crimen se hubiere cometido a bordo de un buque o de una aeronave, el Estado de matrícula del buque o la aeronave;

b) El Estado del que sea nacional el acusado del crimen.

Estos prerrequisitos no se aplican en caso de que la actuación de la Corte sea requerida por el Consejo de Seguridad de las Naciones Unidas.

Además de las condiciones señaladas precedentemente, debe cumplirse también con el principio de complementariedad, que puede dar lugar a una causal de inadmisibilidad. Es así como el artículo 17 del Estatuto dispone que:

1. La Corte teniendo en cuenta el décimo párrafo del preámbulo y el artículo 1, resolverá la inadmisibilidad de un asunto cuando:

a) El asunto sea objeto de una investigación o enjuiciamiento en el Estado que tiene jurisdicción sobre él salvo que éste no esté dispuesto a llevar a cabo la investigación o el enjuiciamiento o no pueda realmente hacerlo;

b) El asunto haya sido objeto de investigación por el Estado que tenga jurisdicción sobre él y éste haya decidido no incoar acción penal contra la persona de que se trate, salvo que la decisión haya obedecido a que no esté dispuesto a llevar a cabo el enjuiciamiento o no pueda realmente hacerlo;

c) La persona de que se trate haya sido enjuiciada por la conducta a que se refiere la denuncia, y la Corte no pueda incoar el juicio con arreglo a lo dispuesto en el párrafo 3 del artículo $20 ; \ldots$

Finalmente, el caso debe revestir cierta gravedad, ya que el artículo 17.1(d) da la facultad a la Corte para declarar inadmisibles los casos que no reúnen la gravedad suficiente para justificar la acción de la Corte.

El que la Corte haya sido creada por medio de un tratado y que su jurisdicción se base en gran medida en el consentimiento de los Estados en cuyo territorio han ocurrido los hechos o cuyos nacionales se encuentran acusados de haber cometido los delitos establecidos en el Estatuto, tiene ciertas importantes implicaciones respecto de los poderes de la Corte. Sarooshi llama la atención sobre el hecho de que, al estar constituida en un tratado y derivar sus poderes de ese tratado, se puede decir que la Corte y sus 
Fuentes - La jurisdicción universal y la Corte Penal Internacional

decisiones no prevalecerían sobre otras obligaciones convencionales de los Estados. ${ }^{24}$ Esto, según el mismo autor, podría entorpecer el cumplimiento de las obligaciones de cooperación asumidas por los Estados Parte. ${ }^{25}$ Así por ejemplo, el propio Estatuto de la Corte dispone en el artículo 98, que:

1. La Corte podrá negarse a dar curso a una solicitud de entrega o de asistencia en virtud de la cual el Estado requerido deba actuar en forma incompatible con las obligaciones que le imponga el derecho internacional con respecto a la inmunidad de un Estado o la inmunidad diplomática de una persona o un bien de un tercer Estado, salvo que obtenga la cooperación de ese tercer Estado para la renuncia a la inmunidad.

2. La Corte no dará curso a una solicitud de entrega en virtud de la cual el Estado requerido deba actuar en forma incompatible con las obligaciones que le imponga un acuerdo internacional conforme al cual se requiera el consentimiento del Estado que envíe para entregar a la Corte a una persona sujeta a la jurisdicciòn de ese Estado, a menos que ésta obtenga primero la cooperación del Estado que envíe para que dé su consentimiento a la entrega.

La relación del Estatuto de la Corte con otros tratados está por verse en relación con los acuerdos que Estados Unidos ha celebrado con algunos Estados Parte, a fin de obtener que estos últimos se comprometan a no transferir nacionales estadounidenses, miembros de las fuerzas de los Estados Unidos en el territorio de esos Estados, a la CPI. Es así como la American Servicemember's Protection Act (ASPA) dictada el año 2002 condiciona la participación de tropas estadounidenses en las operaciones de mantenimiento de la paz de las Naciones Unidas, a la suscripción de un acuerdo con el Estado del territorio donde esas operaciones se lleven a cabo. Asimismo, se prohíbe la cooperación militar con Estados que no consientan en excluir a las tropas estadounidenses de toda transferencia a la CPI. En defensa de la implementación de estos acuerdos Estados Unidos invoca precisamente el artículo 98.2 del Estatuto. ${ }^{26}$ A enero de 2003, Estados Unidos había suscrito este tipo de acuerdos con los siguientes países: Afganistán, República Dominicana, Timor Oriental, El Salvador, Gambia, Honduras, India, Israel, Kuwait, Islas Marshall, Mauritania, Micronesia, Nepal, Palau, Rumania, Tajikistán y Uzbekistán. ${ }^{27}$

El otro problema que identifica Danesh Sarooshi en su artículo se refiere a la relación con las Naciones Unidas. El hecho de haberse constituido por medio de un tratado, en forma independiente de las Naciones Unidas, puede crear dificultades para el financiamiento de la Corte ya que se podría interpretar que, no siendo la CPI un órgano de las Naciones Unidas, es cuestionable si la Asamblea General podría establecer una obligación para los Estados Parte de la Carta de la ONU de contribuir financieramente a la CPI. ${ }^{28}$

\footnotetext{
${ }^{24}$ Sarooshi, D., 'The Statute of the International Criminal Court', 48 International and Comparative Law Quarterly (1999), p. 390.

25 Ibid.

26 'U.S. Bilateral Agreements Relating to ICC', en la Sección "Contemporary Practice of the United States Relating to International Law”, 97 American Journal of International Law (2003), pp. 200-1.

${ }^{27}$ Ibid., p. 201.

${ }^{28}$ Sarooshi, op.cit., p. 394.
} 
Sin perjuicio de estos obstáculos que derivan del hecho de haber sido creada la CPI a través de un tratado independiente de las Naciones Unidas, y que por esa razón no pueda beneficiarse del artículo 103 de la Carta de la ONU, ${ }^{29}$ existen otro tipo de problemas asociados al hecho de que la CPI es un tribunal penal creado por un tratado. Ese tipo de problemas se refiere en particular a la relación que se establecerá o se espera que se establezca entre la jurisdicción de la Corte Penal y la jurisdicción universal que pueden ejercer los Estados.

\section{LA RELACIÓN ENTRE LA CORTE PENAL INTERNACIONAL Y LA JURISDICCIÓN UNIVERSAL.}

Como bien señala la juez ad-hoc Van Den Wyngaert en su opinión disidente en el caso del Arrest Warrant (2002), el Estatuto de la Corte Penal no prohíbe el ejercicio de la jurisdicción universal. ${ }^{30}$ Sin embargo, hay autores que creen que sería conveniente que los Estados restringieran progresivamente el uso de la jurisdicción universal, para dejar la investigación de los hechos y la sanción de los culpables en manos del Estado del territorio donde se cometió el delito o en manos de la CPI. Pese a esta sugerencia de algunos autores, hay que reconocer que habrá casos en que la jurisdicción de la Corte Penal Internacional no será posible de aplicar, y en esa situación, la opción del ejercicio de jurisdicción universal puede ser la única alternativa contra la impunidad de los culpables. Tal sería el caso de un delito cometido en el territorio y por nacionales de un Estado que no es Parte, que no quiere ejercer jurisdicción sobre el hecho, y en que el Consejo de Seguridad no manifiesta interés alguno por requerir la actuación del Fiscal.

Por otro lado, queda sujeto a una futura interpretación el sentido que debe darse a los términos "el Estado que tiene jurisdicción” en el artículo 17 del Estatuto, para los efectos de determinar el ámbito de casos susceptibles de ser conocidos por la Corte. En otras palabras, ¿se activaría el principio de complementariedad si el Estado que ejerce jurisdicción lo hace en base al título de la jurisdicción universal?

A pesar de que efectivamente el Estatuto de la CPI no se manifiesta en contra de la jurisdicción universal, existe una cierta presión para limitar el ejercicio de la jurisdicción universal a través de la CPI. A modo de ejemplo se puede citar una carta enviada por el entonces, Canciller Insulza de Chile al Secretario General de la ONU el 28 de diciembre de 1998, mientras Pinochet permanecía detenido en Londres, en que le señala que Chile tiene interés en que se constituya la CPI y ejerza sus funciones en el más breve plazo y le preocupa que Estados actuando individualmente pretendan usurpar sus competencias. ${ }^{31}$

En la medida que existen presiones para limitar el ejercicio de la jurisdicción universal, ellas podrían encontrar cabida en el seno del Consejo de Seguridad de las

\footnotetext{
${ }^{29} \mathrm{El}$ artículo 103 de la Carta de la ONU dispone que: "En caso de conflicto entre las obligaciones contraídas por los Miembros de las Naciones Unidas en virtud de la presente Carta y sus obligaciones contraídas en virtud de cualquier otro convenio internacional, prevalecerán las obligaciones impuestas por la presente Carta”.

30 Ver párrafo 64 de su opinión disidente.

31 Carta citada por Ramiro Brotóns, en 'La responsabilidad penal individual por crímenes internacionales y el principio de jurisdicción universal', en Escobar (ed.) Creación de una jurisdicción penal internacional (Madrid, 2000), p. 228.
} 
Fuentes - La jurisdicción universal y la Corte Penal Internacional

Naciones Unidas. Podría presentarse entonces el caso que el Consejo de Seguridad quisiera detener el ejercicio de la jurisdicción universal por parte de un determinado Estado y entregarlo al conocimiento de la CPI. Para ello, tendría que requerir la actuación de la Corte y ésta tendría que decretar la no aplicación del artículo 17 relativo al principio de complementariedad. Esa interpretación se podría facilitar mediante la introducción de una aclaración en el propio artículo 17, pactada por los Estados Partes que señalara claramente que el término "Estado que tiene jurisdicción" no incluye a los que adquieren jurisdicción en base al título del carácter universal del delito.

Esto último pone de relieve el mayor peligro que se encierra en el carácter convencional de la CPI. En la medida que el consentimiento que expresan los Estados a nivel internacional al crear tratados no es enteramente representativo de los intereses de la comunidad internacional, se corre el riesgo que las futuras enmiendas, que de seguro se discutirán, respecto del tratado que crea a la CPI se transformen en una instancia para limitar el desarrollo de los intereses básicos de la comunidad internacional. En este contexto, es necesario subrayar que la voluntad que expresan los Estados en el ámbito internacional no necesariamente representa lo que el conjunto de las personas en el mundo habrían decidido de no haber mediado entre ellas y la decisión, un Estado representado básicamente por el poder ejecutivo.

Sin perjuicio de la importancia de la existencia de los Estados en la comunidad internacional actual, el carácter poco democrático de las negociaciones internacionales sugiere que junto a las normas que se establezcan en base al consentimiento de los Estados, debe hacerse espacio también para normas que surgen de la práctica de otros sujetos, tales como los poderes legislativos de los Estados, los poderes judiciales, las organizaciones civiles, y otros. En este contexto, la jurisdicción universal, que se establece en leyes internas de los Estados y es aplicada por tribunales nacionales, es una forma legítima de expresión de la voluntad de los pueblos para sancionar delitos extremadamente graves que atraen el repudio de las diversas comunidades nacionales. El futuro desarrollo del concepto de crímenes contra la humanidad requiere algo más que la legitimidad que le puedan otorgar los poderes ejecutivos de los Estados que negocian los tratados internacionales.

La creación de una Corte Penal Internacional es ciertamente loable y contribuirá en muchos casos a terminar con la impunidad. Sin embargo, la jurisdicción universal es un elemento importante para el desarrollo de una comunidad internacional unida por ciertos intereses básicos comunes. No sería positivo entonces que la Corte se transformara en un vehículo para acallar la voluntad de los pueblos en el ámbito de la justicia internacional. 